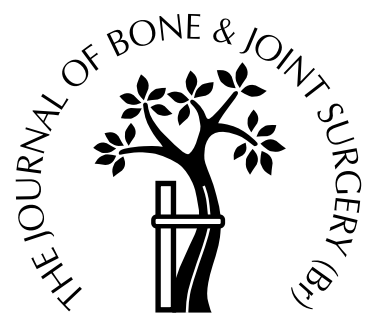

\title{
Wear of enhanced ultra-high molecular-weight polyethylene (Hylamer) in combination with a 22.225 mm diameter zirconia femoral head
}

\author{
B. M. Wroblewski, P. D. Siney, P. A. Fleming \\ From Wrightington Hospital, Wigan, England
}

$\mathbf{W}$ e have prospectively studied the wear of enhanced ultra-high molecular-weight polyethylene (Hylamer) in combination with a zirconia femoral head of $22.225 \mathrm{~mm}$ diameter on a cemented, triple-tapered, collarless, polished stem, the $\mathbf{C}$ Stem.

The 71 patients who underwent total hip arthroplasty had a mean follow-up of six years ( 3 to 8 ). No patient died or was lost to follow-up. The clinical results were excellent with $96 \%$ of patients satisfied. There were no revisions. Two cups were considered to be loose radiologically. One was avulsed from the cement in a skiing accident, with a periprosthetic fracture of the femur, but has remained stable for more than seven years. One femur shows radiological appearances which are compatible with a healing infection. One femoral component is at risk of loosening. The mean rate of penetration of the cup was $0.22 \mathrm{~mm} /$ year $(0.06$ to 0.55$)$.

Our results appear to be within the guidelines set by the National Institute of Clinical Excellence. We have discontinued the use of Hylamer despite excellent clinical results and no revisions to date because the high initial rates of penetration did not settle to the expected low levels within the anticipated time.

J Bone Joint Surg [Br] 2003;85-B:376-9.

Received 2 September 2002; Accepted after revision 15 December 2002

Wear of ultra-high molecular-weight polyethylene (UHMWPE) is one factor which limits the life of a total hip arthroplasty. ${ }^{1}$ The longest surviving prostheses have low

B. M. Wroblewski, FRCS, Professor of Orthopaedic Biomechanics, Consultant Orthopaedic Surgeon

P. D. Siney, BA, Senior Research Fellow

P. A. Fleming, Research Assistant

The John Charnley Research Institute, Wrightington Hospital, Hall Lane, Appley Bridge, Wigan WN6 9EP, UK.

Correspondence should be sent to Miss P. A. Fleming.

(C)2003 British Editorial Society of Bone and Joint Surgery doi.10.1302/0301-620X.85B3.13817\$2.00 rates of penetration. ${ }^{2}$ The use of an alumina ceramic femoral head of diameter $22.225 \mathrm{~mm}$ applied to a Charnley flanged stem, and articulating with chemically cross-linked polyethylene, has provided a decrease in the initially high penetration rate within two to three years. The total penetration did not exceed 0.2 to $0.41 \mathrm{~mm}$ at follow-up to ten years. ${ }^{3}$ Since these materials are no longer available for use in clinical practice it is natural that such a combination should be subjected to more extensive clinical exposure if the long-term problems associated with wear of UHMWPE are to be addressed. We thus undertook a prospective study in order to test a combination of new materials. Extrapolating from earlier results we expected a similar pattern, which is an initial rapid bedding in followed by a steadily declining rate of penetration and a very low total penetration thereafter. $^{3}$

\section{Patients and Methods}

Components. The cups, manufactured from enhanced UHMWPE (Hylamer; DePuy, Leeds, UK) were of an ogee flanged, angle-bore design. ${ }^{4,5}$ The stems, manufactured in high nitrogen stainless steel (Ortron; DePuy), were of a triple taper, polished, C-Stem design with a neck taper of 9 to $10 .^{6}$ The femoral heads were of zirconia (Norton Desmarquest, Paris, France) of diameter $22.225 \mathrm{~mm}$ and were manufactured with three possible placements of $0 \mathrm{~mm},+2 \mathrm{~mm}$ or $-2 \mathrm{~mm}$. The selected femoral head was impacted on to the neck taper immediately before the final reduction of the hip. Operative technique. The senior author (BMW) carried out all the operations in a Charnley Howorth clean-air enclosure with the team wearing total-body exhaust suits. He routinely used a biplanar trochanteric osteotomy. ${ }^{7}$ The acetabulum was prepared with gouges and reamers specially designed to avoid perforating the acetabular floor. The subchondral plate was preserved, if possible, and $5 \mathrm{~mm}$ drill holes were used for the injection of cement. Patients with a superior acetabular deficiency had a solid femoral head autograft with screw fixation. ${ }^{8}$ If the floor of the fovea was smooth, cancellous bone was compacted onto it.

Before cementation, both the acetabulum and medullary canal were washed with a $10 \%$ aqueous povidone iodine solution (Betadine; Seton Health Group, Oldham, UK) and packed with a swab which was soaked in hydrogen pero- 
Table I. The underlying pathology of the hips and the previous hip surgery carried out on 97 hips

\begin{tabular}{lll}
\hline & \multicolumn{2}{l}{ Number of } \\
Underlying hip pathology & 31 & hips \\
\hline Primary osteoarthritis & $19 *$ & 19.6 \\
Secondary osteoarthritis - developmental dyspla- & & \\
sia of the hip & 2 & 2.1 \\
$\quad$ Perthes' disease & 5 & 5.2 \\
$\quad$ Slipped upper femoral epiphysis & 5 & 5.2 \\
$\quad$ Trauma & 2 & 2.1 \\
$\quad$ Acute sepsis & 11 & 11.3 \\
$\quad$ Avascular necrosis & 4 & 4.1 \\
Rheumatoid arthritis & 2 & 2.1 \\
Idiopathic protrusion & & \\
Previous hip surgery & 7 & 7.2 \\
$\quad$ Osteotomy (femoral or pelvic) & 9 & 9.2 \\
$\quad$ Open reduction (developmental dysplasia of & 9 & \\
$\quad$ the hip) & & \\
\hline
\end{tabular}

*In 15 patients a solid femoral head autograft was used with screw fixation in order to supplement a superiorly deficient acetabulum. Some patients had more than a single pathology

Table II. Local and general complications which occurred within one year of surgery, and late complications which occurred more than one year after

\begin{tabular}{lll}
\hline \multirow{2}{*}{ Local } & Delayed wound healing & $\begin{array}{l}\text { Number of } \\
\text { complications }\end{array}$ \\
& Suspected deep infection & 1 \\
& Dislocation & 1 \\
& Trochanteric nonunion & 1 \\
& Fractured femur (see text) & 2 \\
General & Deep-vein thrombosis (clinical diagnosis) & 1 \\
& Pulmonary embolism & 4 \\
& Urinary retention & 2 \\
\multirow{3}{*}{ Late } & Renal failure (recovered) & 8 \\
& Deep infection & 1 \\
& Loose cup (2 radiologically, 1 post-traumatic) & 3 \\
& Loose stem (suspected) & 1 \\
\hline
\end{tabular}

xide. Brushing was not used since it generates shards of plastic. ${ }^{9}$

We used fast-setting cement containing $1 \mathrm{~g}$ of gentamicin per $40 \mathrm{~g}$ mix (CMW; DePuy). The cement was pressurised with a balloon-type pressuriser before insertion of the cup. The flange of the cup was trimmed to size and shape before cementation to enhance pressurisation further. Pressure on the cup was maintained until the cement had fully cured. ${ }^{10}$

Using a hand-held Charnley tapered reamer to open the neck of the femur, the medullary canal was entered through the area of the piriform fossa. Femoral broaches, designed specifically to allow a theoretical cement mantle of $2 \mathrm{~mm}$, were used in order to complete preparation of the medullary canal and to serve as trial stems. A broach one size higher was often used to increase the cavity of the canal, but only if this could be done without force. Calcar clearance was routine. The medullary canal was occluded distally with an intramedullary bone block seated proximal to the anticipated final position of the stem tip, to allow the tip to penetrate it, and to avoid support of the distal stem by cement. $6,11,12$
The medullary canal was gently curetted in order to remove loose cancellous bone. The cement (CMW1; DePuy), which contained $1 \mathrm{~g}$ of gentamicin per $40 \mathrm{~g}$ mix, was introduced from distal to proximal. A proximal seal was used to pressurise the cement which was introduced by a cement gun with a shortened nozzle. The seal was removed and pressurised further using the two-thumb technique. The selected C-Stem was inserted within four to five minutes of mixing, maintaining thumb pressure on the cement at the medial femoral neck. The stem was held with the stem holder until the cement was fully cured. The greater trochanter was reattached using a double-wire crossover and compression spring technique. 7

Patients were usually mobilised on the second postoperative day. They were instructed to bear weight with elbow crutches for six weeks, or three months if a structural femoral head autograft had been used. ${ }^{8}$ Free access was available in case of any problems. At the follow-up examinations, at three months, and then every one or two years with indefinite follow-up as routine, we obtained anteroposterior (AP) radiographs of the pelvis centred over the symphisis pubis and assessed the clinical result using the method of Merle d'Aubigné and Postel ${ }^{13}$ as modified by Charnley. ${ }^{14}$

We recorded the radiological appearances of the cementbone interface on the acetabular side according to Hodgkinson, Shelley and Wroblewski ${ }^{15}$ and on the femoral side according to Pacheco, Shelley and Wroblewski ${ }^{16}$ by using the zones of Gruen, McNeice and Amstutz. ${ }^{17}$ For wear measurements of the Hylamer cup we used the method described by Griffith et al $^{18}$ and popularised by Livermore, Ilstrup and Morrey. ${ }^{19}$ We recorded this as penetration.

Patients. In this prospective study there were 71 patients (97 hips), 34 men and 37 women with a mean age at surgery of 47.8 years (15 to 64) and a mean weight of $72.5 \mathrm{~kg}$ (50 to 108). The underlying hip pathology and previous hip surgery are shown in Table I. The mean operating time was 67 minutes (60 to 120) and the mean length of stay in hospital was 12 days (9 to 19). The mean follow-up at July 2002 was six years (3 to 8$)$.

\section{Results}

The results were excellent. There were no deaths and no patient was lost to follow-up. Of the 71 patients, 96\% (68) were free from pain or had no more than occasional discomfort, $85 \%$ (60) had a full or almost full range of movement and $82 \%$ (58) had normal or nearly normal function. There were no revisions. Postoperative complications are shown in Table II. One patient sustained a spiral periprosthetic fracture of the femur in a ski-ing accident within one year of surgery. This was treated by open reduction and internal fixation. The fracture united uneventfully and the stem was still well fixed seven years later. At the time of the accident the cup was avulsed from the cement mantle into a position which was more open laterally. The cement-bone interface remained intact, and the cup has remained stable to date. 


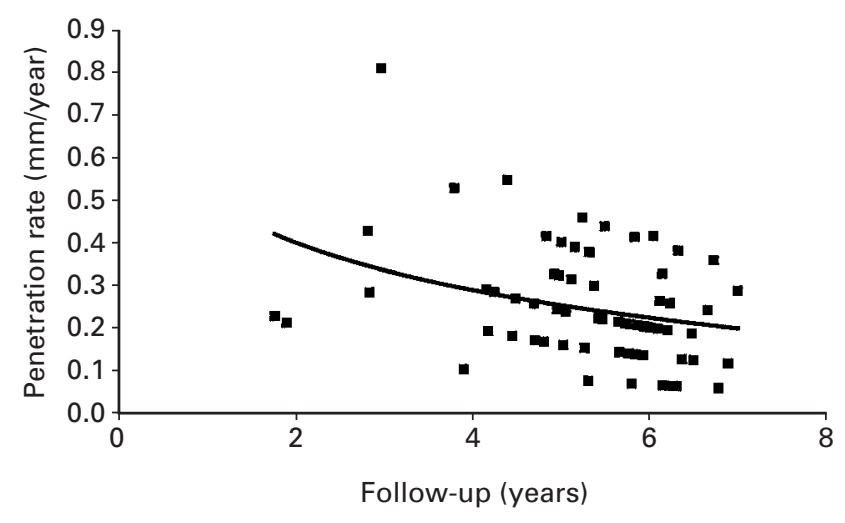

Fig. 1

Penetration rates in relation to follow-up for 71 patients who underwent total hip arthroplasty with cups manufactured from enhanced UHMWPE in combination with a $22.225 \mathrm{~mm}$ diameter zirconia femoral head.

Radiological appearances. For the acetabulum at one year, 47 patients showed no demarcation of the cement-bone interface, 20 had demarcation of the outer third, which measured not more than $1 \mathrm{~mm}$, and three showed demarcation of the outer two-thirds which measured not more than 1 $\mathrm{mm}$. One patient had full demarcation which measured not more than $2 \mathrm{~mm}$ in thickness. None of the cups showed radiological evidence of migration either by change in position or orientation on serial radiographs.

At the latest follow-up 34 patients had no demarcation, 22 had demarcation of the outer third, which was not more than $1 \mathrm{~mm}$ in 21 patients but $3 \mathrm{~mm}$ in one patient. Seven had demarcation in zones 1 and 2, which was not more than 1 mm. Eight hips showed complete demarcation. In six this was not more than $1 \mathrm{~mm}$ and in two it was between 1 and 2 $\mathrm{mm}$. These two cups were regarded as loose. One had a follow-up of 3.8 years and $2 \mathrm{~mm}$ of penetration and the other had a total penetration of $1.2 \mathrm{~mm}$ at seven years.

One femur showed cavitation in Gruen zone 5. This was obvious within one year of surgery and was in the area of a cortical defect, which had been left by a screw used in a previous intertrochanteric osteotomy. The appearances were consistent with infection, formation of cloacae, decompression and possible healing. The follow-up was eight years and the patient was asymptomatic. One other patient showed cavitation in Gruen zone 2, which appeared after the first year and was probably due to inadequate fixation.

Wear. This was measured as penetration. The mean rate of penetration was $0.22 \mathrm{~mm} /$ year $(0.06$ to 0.55$)$. The total penetration was $1.29 \mathrm{~mm}$ (0.4 to 3.6) at a mean follow-up of six years (3 to 8 ). The rate of change in the rate of penetration of the Hylamer cup in relation to follow-up is shown in Figure 1. A clinical example with a follow-up at five years is shown in Figure 2.

\section{Discussion}

The early clinical results using a zirconia femoral head of diameter $22.225 \mathrm{~mm}$ articulating with a Hylamer socket have been excellent, although the anticipated rates of penetration have not materialised. The mean penetration rate was approximately twice as high as that obtained with the 22.225 $\mathrm{mm}$ diameter stainless-steel Charnley monoblock femoral

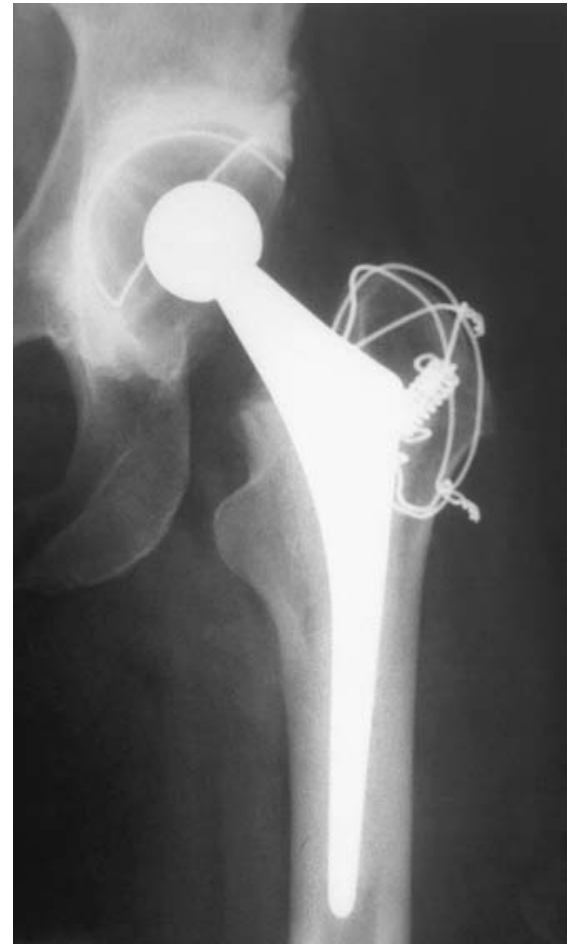

Fig. 2a

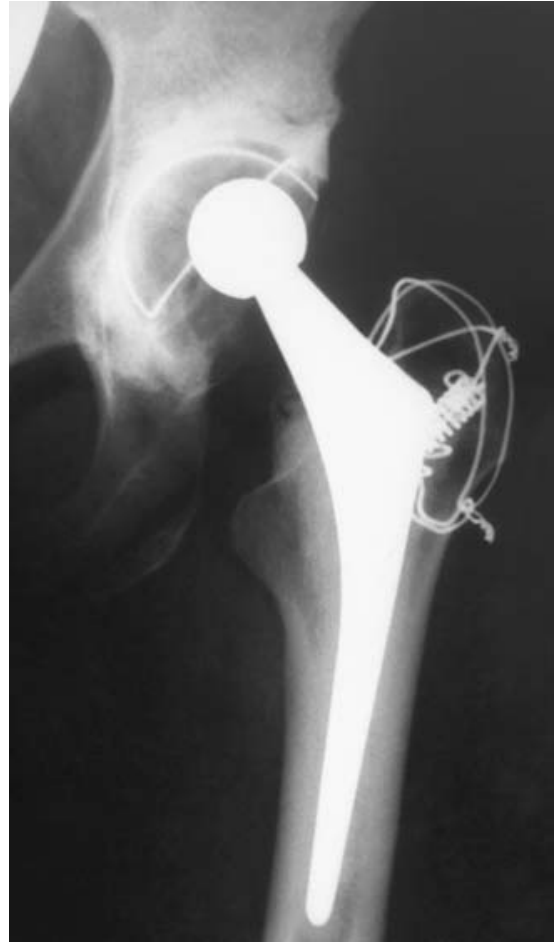

Fig. $2 b$
Radiographs of a 43-year-old woman with preoperative developmental dysplasia of the hip a) immediately after operation and b) after five years when a total penetration of 2.5 $\mathrm{mm}$ can be seen. 
head articulating with a standard UHMWPE socket. Our results show a fundamental difference from those published recently. ${ }^{20}$ We have not had a revision to date, but with the high rate of penetration, revisions will no doubt follow. ${ }^{21}$

There are three possible reasons for the difference between our series with no revisions at a mean follow-up of six years ( 3 to 8 ) and the study by Norton et $\mathrm{al}^{20}$ who reported "a failure rate of $67.6 \%$ at five years... because of aseptic loosening". These are the size of the zirconia head, $22.225 \mathrm{~mm}$ as opposed to $28 \mathrm{~mm}$, the triple-tapered, polished C-Stem compared with the Elite Plus, and possible differences in the surgical technique.

If the materials are identical the rate of penetration should be inversely proportional to the diameter of the femoral head. This does not appear to be so. The $28 \mathrm{~mm}$ diameter femoral head had a rate of penetration which was almost three times higher. Could this be explained by the 'shelf life' of the Hylamer cup? All our cups, except one, were implanted within one year of supply and thus within their 'shelf life'. Is the 'shelf life' in fact shorter than anticipated? The stem design, Elite Plus, is basically that of a flanged Charnley with an extended range of sizes. ${ }^{6}$ Why should this result in early failures? We have achieved $99 \%$ survival at ten years in patients under the age of 51 years using the Charnley round back and flanged, matt finished stems. ${ }^{22}$ Finally, there is the question of surgical technique. We have described our method.

A combination of a zirconia femoral head of $22.225 \mathrm{~mm}$ articulating with a Hylamer cup has given clinical results which do not differ from those obtained with conventional materials. This is not unexpected. This combination, however, has not lived up to its expectations since the rate of penetration is on average twice as high as that for the materials which it was intended to replace. Nevertheless, our results appear to be within the limits set by the National Institute of Clinical Excellence. ${ }^{23}$ We have, however, discontinued the use of Hylamer, not because of poor clinical results or a high incidence of revisions or even because of the high initial penetration rates which were expected, based on previous experience, ${ }^{3,21}$ but because the high initial rates of penetration did not settle to the expected low levels within the anticipated period of time.

Research is supported by the Peter Kershaw and John Charnley Trusts.

No benefits have been received or will be received from a commercial party related directly or indirectly to the subject of this article.

\section{References}

1. Wroblewski BM. Charnley low friction arthroplasty in patients under the age of 40 years. In: Sevastik J, Goldie I, eds. The young patient with degenerative hip disease. Stockholm: Almqvist \& Wiksell, 1985:197-201.
2. Wroblewski BM, Fleming PA, Siney PD. Charnley low-frictional torque arthroplasty of the hip: 20-30 year results. J Bone Joint Surg [Br] 1999;81-B:427-9.

3. Wroblewski BM, Siney PD, Dowson D, Collins SN. Prospective clinical and joint simulator studies of a new total hip arthroplasty using alumina ceramic heads and cross-linked polyethylene cups. J Bone Joint Surg [Br] 1996;78-B:280-5.

4. Shelley P, Wroblewski BM. Socket design and cement pressurisation in the Charnley low-friction arthroplasty. J Bone Joint Surg [Br] 1988;70-B:358-63.

5. Wroblewski BM. Revision surgery in total hip arthroplasty. SpringerVerlag, London, 1990, 43-44.

6. Wroblewski BM, Siney PD, Fleming PA. Triple taper polished cemented stem in total hip arthroplasty: rationale for the design, surgical technique and 7 years of clinical experience. J Arthroplasty 2001;16(Suppl 1):37-41.

7. Wroblewski BM, Shelley P. Reattachment of the greater trochanter after hip replacement. J Bone Joint Surg [Br] 1985;67-B:736-40.

8. Bobak P, Wroblewski BM, Siney PD, Fleming PA, Hall R. Charnley low friction arthroplasty with an autograft of the femoral head for developmental dysplasia of the hip: the 10- to 15-year results. J Bone Joint Surg $[\mathrm{Br}]$ 2000;82-B:508-11.

9. Germain MA, Tipper JL, Ingham E, et al. Analysis of debris from brushing the femoral canal with a plastic brush: a potential cause of loosening in total hip replacement. Proc Inst Mech Eng $(H)$ 1999;213:503-6.

10. Charnley J. Low friction arthroplasty of the hip: theory and practice. Springer-Verlag, Germany, 1979;99.

11. Wroblewski BM, Siney PD, Fleming PA, Bobak P. The calcar in cemented stem fixation in total hip arthroplasty. J Bone Joint Surg [Br] 2000;82-B:842-5.

12. Wroblewski BM, van der Rijt A. Intramedullary cancellous bone block to improve femoral stem fixation in Charnley low-friction arthroplasty. J Bone Joint Surg [Br] 1984;66-B:639-44.

13. Merle d'Aubigné R, Postel M. Functional results of hip arthroplasty with acrylic prosthesis. J Bone Joint Surg [Am] 1954;36-A:451-75.

14. Charnley J. The long term results of low friction arthroplasty of the hip performed as a primary intervention. J Bone Joint Surg [Br] 1972;54B:61-76.

15. Hodgkinson JP, Shelley P, Wroblewski BM. The correlation between the roentgenographic appearance and the operative findings at the bonecement junction of the socket in Charnley low friction arthroplasties. Clin Orthop 1988;228:105-9.

16. Pacheco V, Shelley P, Wroblewski BM. Mechanical loosening of the stem in Charnley arthroplasties: identification of the "at risk" factors. $J$ Bone Joint Surg [Br] 1988;70-B:596-9.

17. Gruen TA, McNeice GM, Amstutz HC. "Modes of failure" of cemented stem-type femoral components: a radiographic analysis of loosening. Clin Orthop 1979;141:17-27.

18. Griffith MJ, Seidenstein MK, Williams D, Charnley J. Socket wear in Charnley low friction arthroplasty of the hip. Clin Orthop 1978;137:37-47.

19. Livermore J, Ilstrup D, Morrey B. Effect of femoral head size on wear of the polyethylene acetabular component. J Bone Joint Surg [Am] 1990;72-A:518-28.

20. Norton MR, Yarlagadda R, Anderson GH. Catastrophic failure of the Elite Plus total hip replacement with a Hylamer acetabulum and zirconia ceramic femoral head. J Bone Joint Surg [Br] 2002;84-B:631-5.

21. Wroblewski BM. Revision surgery in total hip arthroplasty: surgical technique and results. Clin Orthop 1982;170:56-61.

22. Wroblewski BM, Fleming PA, Hall RM, Siney PD. Stem fixation in the Charnley low friction arthroplasty in young patients using an intramedullary bone block. J Bone Joint Surg [Br] 1998;80-B: 273-8.

23. NICE Technology Appraisal Guidance No.2. April 2002. 